\title{
RANDOMNESS IN TAX ENFORCEMENT
}

\author{
Suzanne SCOTCHMER \\ University of California, Berkeley, CA 94720, USA \\ Joel SLEMROD* \\ University of Michigan, Ann Arbor, MI 48109, USA
}

Received August 1987, revised version received August 1988

\begin{abstract}
When there is tax evasion, increased randomness about how much taxable income an auditor would assess generally leads to higher reported income and more rcvenuc. When reducing randomness is costly, optimality requires some randomness in assessed taxable income. Even if reducing randomness is costless, taxpayers may prefer some randomness when the increased revenue can be rebated, so that the government's revenue stays fixed.
\end{abstract}

\section{Introduction}

When tax reporting is voluntary as in the U.S. income tax system, enforcement of the tax code is undertaken primarily through occasional audits, with penalties often assessed if the taxpayer is discovered to have underreported taxable income. Most studies of optimal tax enforcement focus on the frequency of audits and the penalty for evasion. This paper discusses another aspect of the tax system that affects underreporting: that taxable income as it would be assessed by an auditor is a random variable. Taxpayers' perception that tax assessments are random was documented, for example, in the taxpayer survey conducted by Yankelovich, Skelly and White, Inc. (1984), in which only 48 percent of taxpayers thought that IRS decisions were consistent from one taxpayer to the next (p. 149).

The randomness has two sources. First, the tax code itself is imprecise. Second, for any given tax code, the tax administration agency can alter the

*NSF Grant SES 86-10021 supported this research. We thank Frank Cowell for helpful comments. 
extent of randomness by training its auditors more or less uniformly or by issuing (or not) detailed regulations. We investigate the welfare and revenue consequences of the tax administration's efforts to reduce randomness, assuming the imprecision of the tax code is fixed. ${ }^{1}$

We find that, when reducing randomness is costly, ${ }^{2}$ it is not optimal to remove all randomness in tax liability assessments. Also, the enforcement agency's preferred amount of randomness differs according to whether the enforcement policy is chosen to maximize revenue or to maximize welfare.

Section 2 below shows in a simple model that with the probability of audit and fines fixed, randomness in assessed taxable income generally enhances revenue. ${ }^{3}$ Section 3 shows that optimality requires some randomness whenever reducing randomness is costly. ${ }^{4} \mathrm{~A}$ marginal increase in randomness, from an initial point of none, imposes no loss in expected utility and does not change the amount of revenue collected. Hence, it is socially desirable to save costs by allowing some randomness in tax liability assessments, and to rebate the savings to taxpayers. Since this is true for every tax rate, it follows that the optimal combination of tax code and enforcement policy requires some randomness.

Section 4 discusses the optimal amount of randomness with two different assumptions about the available policy instruments. First, we discuss the fact that a fixed amount of revenue can be collected with high frequency of audits and little randomness, or with low frequency of audits and high randomness, when tax and fine rates are fixed. Since costs can be saved by increasing randomness and decreasing the probability of audit, the cost-minimizing policy requires as much randomness as possible. With risk-averse taxpayers, one therefore might suspect that the cost-minimizing enforcement policy does not maximize taxpayer welfare, even if the cost-savings are rebated through tax reductions. This depends on how fast the probability of audit can fall as randomness increases. In section 4 we also discuss the second-best problem that the audit budget is held fixed and additional revenues collected due to randomness are rebated to taxpayers (possibly as an increase in public

\footnotetext{
${ }^{1}$ Randomness could also be reduced by changing the tax law itself. For example, the U.S. Treasury Department's tax reform proposal of November 1984, Tax Reform for Fairness, Simplicity, and Economic Growth, stressed the importance of simplifying the tax code. It further recognized that simplicity in taxation has several dimensions, among them that 'under a simple system, most responsible taxpayers would be more certain of their tax liabilities'.

${ }^{2}$ One could imagine circumstances in which reducing variability in assessments is not costly, and our conclusion does not apply then. For example, it may be that increased clarity of the tax code in some cases may reduce the cost of training auditors, and on net save costs.

${ }^{3}$ This corroborates the intuition of Roberts (1979), who argued that uncertainty of true tax liability ensures conservative decision-making by risk-averse agents, and may therefore he preferable to the alternative of having explicit rules for every possible situation.

${ }^{4}$ The argument is similar to Baldry's (1984) argument that 'complete enforcement of income tax laws, designed to reduce income tax evasion to zero, is inefficient when the marginal cost of enforcement is positive.'
} 
services)..$^{5}$ Taxpayers may prefer some randomness in tax assessments even if reducing randomness is costless. ${ }^{6}$ Rebates might smooth consumption between states of the world in which the taxpayer is and is not audited, thus providing a benefit. ${ }^{?}$

\section{Uncertainty and revenue}

We assume that, conditional on audit, the auditor may assess one of two incomes, $m-d$ or $m+d$, as the taxable income, each with probability onehalf. The parameter $m$ is not true taxable income; rather, it is merely the mean of a distribution of possible assessed incomes. There is a maximum possible value of $d$, which is determined by the imprecision of the tax code. We assume that the IRS cannot instruct auditors always to err in favor of the IRS'. Aside from the fact that the IRS may be concerned with equity, and therefore eschew this obvious means to enhance revenue, auditors may differ in their understandings of the tax code and have honest disagreements with each other, although each thinks he or she is right. The instruction to "err in favor of the IRS' would then have no effect. It is costly to resolve these disagreements ex ante. This is the cost modeled below.

In the United States, the taxpayer himself could mitigate the uncertainty either by asking the IRS for a binding decision ex ante, or by appealing to the Tax Court ex post if the assessment were high. Ex ante decisions have no relevance for other taxpayers, and the legal fees are often in the neighborhood of $\$ 10,000$ [Lee (1987)]. We assume that, due to costliness, taxpayers do not take advantage of this right. Ex post appeals are also rare, since they are often more costly than the amount of tax that might be saved. In addition, appeal does not eliminate the randomness because, when the tax code is truly imprecise, the decision of the Tax Court is unpredictable. Appeals would change the probabilities of the high and low assessments, since a taxpayer would only appeal if the assessment were high. The probability of a high assessment, conditional on appeal, would then be lower

\footnotetext{
${ }^{5} \mathrm{We}$ assume that the increased revenue is returned to taxpayers as a lump-sum rebate, rather than as a lowered tax rate. This simplification has been used frequently in the literature. See, for example, Slemrod and Yitzhaki (1987) and Cowell (1985). There are two differences between lowering the tax rate and making lump-sum rebates or increasing public goods. First, the lumpsum rebate does not depend on whether the taxpayer is audited or the amount of taxable income he is assessed. The benefit of a reduced tax rate depends on whether the taxpayer is audited. Second, lump-sum rebates and reduced tax rates have slightly different impacts on the taxpayer's reported income.

${ }^{6}$ But we show in our earlier paper [Scotchmer and Slemrod (1987)] that in this regime the optimal variance in assessed income is finite.

${ }^{7}$ That expected utility may increase with uncertainty even when there is no cost saving is reminiscent of the results of Weiss (1976), Stiglitz (1982) and Chang and Wildasin (1987), who found that when taxation introduces distortions to the labor market, randomness in tax liability may improve welfare. The welfare benefit of increased labor supply may outweigh the welfare loss of increased uncertainty. This mechanism is absent in our model.
} 
than one-half. Since our results do not depend on the particular probabilities of each assessment (we consider probabilities of one-half for simplicity), this complication would not change the results. ${ }^{8}$

Since different auditors would assess different taxable income, honest reporting has no meaning, and it is impossible (unless $d=0$ ) for the taxpayer to take a riskless position. If he or she reported the maximum income in the support of possible assessed incomes, which is $m+d$ in our simple model, he or she would avoid fines, but would often find when audited that 'true taxable income' was overreported and a rebate is forthcoming.

We assume a linear tax rate $t$, and that fines are levied at rate $f$ on unreported tax liability when an audit reveals that income has been underreported. The probability of audit is $p$.

If the taxpayer is assessed higher taxable income than reported, he or she pays the tax due on assessed income plus a fine on the unreported income. If the taxpayer is assessed lower taxable income than reported, he or she is rebated the overpaid tax, but is not rebated a 'reward' at the fine rate. We shall use the notation $w_{\mathrm{NA}}, w_{\mathrm{AL}}, w_{\mathrm{AH}}$ to refer to the net incomes available to the taxpayer in the case of no audit, audit with a low assessment, $m-d$, and audit with a high assessment, $m+d$. Letting $y$ be the taxpayer's gross income, $w_{\mathrm{NA}}=y-t r, \quad w_{\mathrm{AH}}=y-t(m+d)-t f(m+d-r), \quad$ and $\quad w_{\mathrm{AL}}=y-t(m-d) \quad$ or $w_{\mathrm{AL}}=y-t(m-d)-t f(m-d-r)$, according to whether reported income $r$ is greater or less than $m-d$. When $r<m-d, w_{\mathrm{AH}}<w_{\mathrm{AL}}<w_{\mathrm{NA}}$. When $r>m-d$, $w_{\mathrm{AH}}<w_{\mathrm{NA}}<w_{\mathrm{AL}}$.

Since the taxpayer's reported income will typically depend on $d$ as well as on the probability of audit and fine rate, the amount of revenue collected will also depend on $d$. We show that when taxpayers have nonincreasing absolute risk aversion, ${ }^{9}$ reported income rises with $d$, and therefore the amount of revenue collected rises with $d$ also. Taxpayers choose reported income $r(d, p, t)$ to maximize expected utility, knowing that an audit is possible. The optimal report $r(d, p, t)$, which is less than $m+d,{ }^{10}$ maximizes expected utility,

\footnotetext{
${ }^{8} \mathrm{~A}$ third possibility is that the taxpayer can seek tax advice from a professional tax preparer or advisor to resolve his or her uncertainty. Scotchmer (1988a, 1988b) shows that resolving the taxpayer's uncertainty ex ante will decrease the taxpayer's expected payments. But in the context we discuss here, seeking tax advice will not resolve uncertainty, since the randomness is due to auditors' judgments rather than to the taxpayer's ignorance.

${ }^{9}$ Decreasing absolute risk aversion implies that in the choice between a safe asset and a risky asset, the risky asset is a normal good. Therefore decreasing absolute risk aversion is often taken as a reasonable assumption about preferences. However, when assessed income is a random variable, there is no safe asset.

${ }^{10} \mathrm{~A}$ report of $m+d$ always dominates a larger report, because we assume fines cannot be negative. Reporting income greater than $m+d$ increases taxes when the taxpayer is not audited, and has no advantage when the taxpayer is audited. We allow the taxpayer to report negative income. As one can see from the first-order conditions (4) and (5) below, the taxpayer will not do so if it forces income in the state of the world that he is audited and assessed high to be close to zero, provided the marginal utility of income goes to infinity as income goes to zero.
} 
$E U[r, d, p, t]$. Expected utility is a concave function of $r$, provided $U[\cdot]$ is concave: ${ }^{11}$

$$
E U[r, d, p, t]=(1-p) U\left[w_{\mathrm{NA}}\right]+(p / 2) U\left[w_{\mathrm{AL}}\right]+(p / 2) U\left[w_{\mathrm{AH}}\right],
$$

where we must substitute the correct expression for $w_{\mathrm{AL}}$ according to whether $r$ is less than or greater than $m-d$.

The expected revenue collected is just the taxpayer's expected payment:

$$
\begin{aligned}
& R[r(\cdot), d, p, t]=t[1-p(1+f)] r(\cdot)+m p t(1+f), \quad \text { if } r(\cdot)<m-d, \\
& R[r(\cdot), d, p, t]=t[1-(p / 2)(2+f)] r(\cdot)+m t(p / 2)(2+f)+(p / 2) t f d, \\
& \quad \text { if } r(\cdot) \geqq m-d .
\end{aligned}
$$

To show that revenue increases with $d$, we must characterize the optimal report $r(\cdot)$. The optimal report $r(\cdot)$ satisfies (4) or (5), according to whether $r(\cdot)$ is smaller or larger than $m-d \cdot:^{12}$

$$
\begin{aligned}
& -(1-p) U^{\prime}\left[w_{\mathrm{NA}}\right]+(p / 2) f U^{\prime}\left[w_{\mathrm{AL}}\right]+(p / 2) f U^{\prime}\left[w_{\mathrm{AH}}\right] \geqq 0, \\
& =0, \quad \text { if } r(\cdot)<m-d, \\
& -(1-p) U^{\prime}\left[w_{\mathrm{NA}}\right]+(p / 2) f U^{\prime}\left[w_{\mathrm{AH}}\right]=0, \quad \text { if } m-d<r(\cdot)<m+d, \\
& \leqq 0, \quad \text { if } r(\cdot)=m-d, \\
& \geqq 0, \quad \text { if } r(\cdot)=m+d .
\end{aligned}
$$

Proposition 1. Suppose preferences exhibit nonincreasing absolute risk aversion and $p \leqq 1 /(1+f) .^{13}$ Then, if $d>0$ and $r(\cdot)<m-d \quad$ or

${ }^{11}$ The function $E U(r)$ (with the parameters $d, p$ and $t$ fixed) is the minimum of the two functions

and

$$
\begin{aligned}
f(r)= & (1-p) U(m-t r)+(p / 2) U(m-t(m-d)-t f(m-d-r)) \\
& +(p / 2) U(m-t(m+d)-t f(m+d-r))
\end{aligned}
$$

$$
g(r)=(1-p) U(m-t r)+(p / 2) U(m-t(m-d))+(p / 2) U(m-t(m+d)-t f(m+d-r)) .
$$

That is, $E U(r)=\min \{f(r), g(r)\}$. A function that is the minimum of two concave functions is concave.

${ }^{12}$ Since expected utility is a concave function of $r$, the derivative is nonincreasing. It follows that the $r(\cdot)$ which satisfies (4) and (5) is unique.

${ }^{13}$ If $d=0$ (and honestly reporting $r=m$ is therefore equivalent to holding a safe asset), the taxpayer will report $r<m$ when $p<1 /(1+f)$, because the expected return to underreporting income is positive. If $p=1 /(1+f)$, the taxpayer will prefer to report $r=m$. Since probability of audit $1 /(1+f)$ makes underreporting income at $d=0$ a 'fair bet', it is reasonable to restrict $p$ to be less than $1 /(1+f)$. 
$m-d<r(\cdot) \leqq m+d,{ }^{14}$ revenue increases with $d$. If $d=0$, a marginal increase in $d$ does not affect revenue.

Proof. We discuss this separately for the domains on which $r(\cdot)<m-d$, $m-d<r(\cdot)<m+d$ and $r(\cdot)=m+d$. First, suppose that $r(\cdot)<m-d$, which can only occur if $p<1 /(1+f)$. Differentiating (4) implicitly,

$$
r_{d}(\cdot)=\frac{(p / 2) f(1+f)\left[U^{\prime \prime}\left[w_{\mathrm{AH}}\right]-U^{\prime \prime}\left[w_{\mathrm{AL}}\right]\right]}{(1-p) U^{\prime \prime}\left[w_{\mathrm{NA}}\right]+(p / 2) f^{2}\left[U^{\prime \prime}\left[w_{\mathrm{AH}}\right]+U^{\prime \prime}\left[w_{\mathrm{AL}}\right]\right]}, \quad \text { if } r(\cdot)<m-d
$$

Reported income and revenue increase with $d$ as long as the second derivalive of utility is increasing, as with nonincreasing absolute risk aversion.

Suppose next that $m-d<r(\cdot)<m+d$. Differentiating (5) implicitly, the responsiveness of reported income to randomness is given by the following expression:

$$
r_{d}(\cdot)=\frac{(p / 2) f(1+f) U^{\prime \prime}\left[w_{\mathrm{AH}}\right]}{(1-p) U^{\prime \prime}\left[w_{\mathrm{NA}}\right]+(p / 2) f^{2} U^{\prime \prime}\left[w_{\mathrm{AH}}\right]}, \quad \text { if } m-d<r(\cdot)<m+d
$$

This expression is always positive, and according to (3), revenue rises with d..$^{15}$

On an interval of values $d$ for which $r(\cdot)=m+d$, the derivative of revenue, eq. (3), with respect to $d$ is positive. If $p<1 /(1+f)$, then at $d=0, r(\cdot)<m-d$ and an incremental amount of uncertainty will affect neither reported income nor revenue, according to eqs. (2) and (6), since $w_{\mathrm{AH}}=w_{\mathrm{AL}}$. If $p=1 /(1+f)$, then $r(\cdot)=m-d$ in a neighborhood of $d=0$, according to the following lemma, and an increase to $d$ will reduce reported income. But this will not affect revenue, since, substituting $r(0, p, t)=m-d$ into revenue function (2) or (3), the derivative of revenue is $[1-p(1+f)] r_{d}(\cdot)=0$. Q.E.D.

\footnotetext{
${ }^{14}$ There may be an interval of values on which $r(\cdot)=m-d$, athough for $d$ sufficiently large, $m-d<r(\cdot)$. At $r=m-d$, the marginal utility of increasing $r$ jumps down discontinuously by the amount $(p f / 2) U^{\prime \prime}[y-t(m-d)]$. This is because, for $r<m-d$, increasing $r$ reduces the fine if $m-d$ is assessed, but, when $r>m-d$, increasing $r$ only increases the rebate in the event that $m d$ is assessed. The optimal report $r(\cdot)$ equals $m-d$ if these marginal utilities are on opposite sides of zero. For some values of $d$, a marginal increase in $d$ will preserve the 'jump' at $r(\cdot)=m-d$. If $p<1 /(1+f)$, then revenue decreases with $d$ on an interval where $r(\cdot)=m-d$.

Beck and Jung (1987) show that, when $d$ is a continuous variable, reported income (and therefore revenue) may decrease when the dispersion of $d$ increases. This occurs because one marginal benefit of increasing reported income is that it reduces the probability that a fine will be assessed. (In our model, this probability is reduced only when $r$ crosses the threshold of $m-d$.) For a taxpayer reporting below $m$, an increased dispersion of possible assessed incomes decreases the likelihood that the reported income will be declared insufficient and a fine assessed, so that this component of marginal benefit may be reduced, leading to a lower report.

${ }^{15}$ If $p \leqq 1 /(1+f)$, then $[1-(p / 2)(2+f)]$ is non-negative.
} 
Lemma 1. If $p=1 /(1+f)$ and utility exhibits nonincreasing absolute risk aversion, then $r(d, p, t)=m-d$ for $d$ in a neighborhood of $d=0$.

Proof. See the appendix.

The intuition behind Proposition 1 is best seen by analogy to a problem of portfolio choice. Allingham and Sandmo's (1972) paper introduced this framework for the case that 'true' taxable income is defined. In that case, understating income is equivalent to purchasing a risky asset which pays off in the event the return is unaudited and suffers a loss in the event that an audit occurs. When there is randomness in assessed taxable income, the taxpayer is in essence forced to hold a risky asset regardless of the reported income. The amount of income reported generates another risky asset, whose value to the taxpayer depends on the extent of randomness in assessment. In other words, one must consider the covariance between the involuntarily held random-assessment asset and the asset created by the income report.

Consider first the case where the optimal report is greater than the low assessed income $(r>m-d)$. For given $r$, an increase in $d$ reduces net income in the audited, high assessment state of the world. This increases the statecontingent marginal utility of increasing $r$. An increase in $d$ also increases net income in the audited, low assessment state of the world, but income in this state is not affected by $r$, since the taxpayer is simply liable for $t(m-d)$, regardless of reported income. Overall, an increase in $d$ increases the marginal utility of increasing $r$ in the audited, high-assessment state of the world and leaves it unchanged in the other states. Therefore, the optimal report increases when $d$ increases.

When the optimal report is less than the low assessed income, an increase in $d$ alters the riskiness of the taxpayer's portfolio by decreasing income in the worst state of the world (audited, high assessment) and increasing income by the same amount in the second-best state of the world (audited, low assessment). This affects the state-contingent marginal utility of increasing $r$ in both audited states of the world. An increase in $r$ increases income in these two states identically. As long as the second derivative of utility is increasing, as with nonincreasing absolute risk aversion, the increase in the marginal utility of $r$ in the high assessment state outweighs the decrease in the marginal utility of $r$.

In both cases, being forced to hold more of the random-assessment asset makes the reported-income asset more attractive. The reported-income asset pays off in the audited, high assessment state of the world, in which the marginal utility of income increases.

We cannot conclude from Proposition 1 that the collection agency can increase revenue simply by flipping coins, because the randomness cannot exceed that permitted by the tax code. Furthermore, a net-revenue- 
maximizing tax collection agency would always prefer to increase randomness by laying off members of its auditor-training or regulation-writing staff, and thereby save costs, rather than by flipping coins. But even so, the observation that revenue can be increased costlessly by introducing randomness reinforces one of the main points of this paper: that choosing an enforcement policy to maximize revenue does not necessarily serve the public interest. The revenue-maximizing enforcement policy is not the welfaremaximizing policy. We now consider how much randomness is optimal.

\section{Some randomness is optimal}

We now argue that, when clarifying the tax code is costly, some randomness is optimal irrespective of how or why the other tax and enforcement parameters are selected. This is because a marginal increase in $d$ from $d=0$ saves costs without reducing expected utility or increasing revenue. The possibility that $d=0$ simply means that the tax administration agency has sufficient latitude, through uniform training of auditors and issuance of rulings, to clarify all ambiguities in the tax code. Presumably, the cost involved in eliminating all uncertainty $(d=0)$ would be large, since it requires that all ambiguous issues be resolved ex ante, even those that are rarc. Conversely, the cost saving if some uncertainty is allowed $(d>0)$ is also large.

The following lemma is required:

Lemma 2. At $d=0$, and provided $p \leqq 1 /(1+f),{ }^{16}$ the derivative of $E U[r(d, p, t), d, p, t]$ with respect to $d$ is zero. That is, a marginal increase in randomness does not decrease expected utility.

Proof. Suppose first that $p<1 /(1+f)$, so that taxpayers report $r(0, p, t)<m$ when $d=0$. The partial derivative with respect to $r$ is zero because of the taxpayer's optimizing choice. Therefore we only need to show that the partial with respect to $d$ is zero. The derivative with respect to $d$ is:

$$
(p / 2) t(1+f)\left[U^{\prime}\left[w_{\mathrm{AL}}\right]-U^{\prime}\left[w_{\mathrm{AH}}\right]\right] \text {, which is zero when } w_{\mathrm{AL}}=w_{\mathrm{AH}} \text {. }
$$

For the case that $p=1 /(1+f)$, we again need Lemma 1 , that $r(d, p, t)=$ $m-d$ for small $d$. Substituting $r(d, p, t)=m-d$ into expected utility, it becomes $(1-p) U[y-t(m-d)]+(p / 2) U[y-t(m-d)]+(p / 2) U[y-t(m+d)-$ $2 t d f]$. Using the facts that $p=1 /(1+f)$ and $w_{\mathrm{AL}}=w_{\mathrm{AH}}=w_{\mathrm{NA}}$, the derivative with respect to $d$ at $d=0$ is zero. Q.E.D.

\footnotetext{
${ }^{16}$ For purposes of Proposition 2 we do not need to consider $p>1 /(1+f)$, because, if $d=0$, the optimal $(d, p, t)$ would require $p \leqq 1 /(1+f)$. Probability $p=1 /(1+f)$ elicits truthful reporting, and a higher probability would be wasteful.
} 
Proposition 2. Suppose that the marginal cost of reducing randomness is positive, so that increasing randomness saves costs. Then $d=0$ is not optimal.

Proof. We showed in Proposition 1 and Lemma 2 that at $d=0$, a costless marginal increase in randomness does not change revenue or decrease expected utility. That is, the partial derivative of $E U[r(\cdot), d, p, t]$ with respect to $d$ is zero. The costs saved by increasing $d$ can be rebated to the taxpayer, either as a lump-sum rebate or a reduction in the tax rate, both of which increase expected utility. Q.E.D.

Since this is true for all tax rates $t$ and probabilities of audit $p$, it implies that the optimal combination $(t, p, d)$ requires $d>0$ whenever reducing randomness is costly. It is optimal to increase randomness until the marginal loss in expected utility is just balanced by the cost-saving.

\section{The optimal amount of uncertainty}

Here we discuss two second-best problems relating to the optimal amount of randomness. The first is the problem of enforcement, with a fixed tax code. Since revenue typically rises with the probability of audit and typically rises with randomness (at least for large enough $d$ ), there are many combinations of $p$ and $d$ that will collect a fixed amount of revenue. Since raising $d$ and reducing $p$ saves cost, the cost-minimizing enforcement policy may require as much randomness as possible (that is, the tax authority does nothing to reduce the imprecision of the tax code), with small probability of audit. ${ }^{17}$

But randomness reduces expected utility by imposing ex ante uncertainty. Whether or not high variance in assessed tax liability maximizes taxpayer welfare, as well as minimizing the enforcement cost, depends on how fast expected utility falls with randomness, relative to the cost savings. Our previous paper [Scotchmer and Slemrod (1987)] gives two examples, showing that this may go either way.

We notice that the question of whether high variance is the optimal enforcement policy is similar to the question of whether it is optimal to increase fines without bound, when the two enforcement parameters are the fine rate and audit probability, rather than uncertainty and audit probability, as here. In the tradeoff between audit-probability and fines (with no randomness) revenue in amount $t m$ can always be collected by choosing $p(f)=1 /(1+f)$, since taxpayers then report income $m$. (Underreporting income is then a 'fair bet'.) Enforcement costs can always be reduced without any loss to taxpayer utility, by choosing $f$ larger and $p(f)$ smaller (but never

\footnotetext{
${ }^{17}$ If there is an upper bound on the feasible $d$ because negative income is not allowed, then the cost-minimizing amount of uncertainty might be the lowest value $d$ for which $r(\cdot)=m-d$. This is because, when $p<1 /(1+f)$, revenue decreases with $d$ on the domain where $r(\cdot)=m-d$. Increases in $d$ on that domain save costs, but decrease revenue, necessitating a simultaneous increase in the probability of audit, rather than a decrease.
} 
quite zero). Thus, there is no conflict between the goals of minimizing enforcement cost and maximizing taxpayer utility, provided the tax rate has been set such that $\mathrm{tm}$ is equal to the revenue requirement. In contrast, 'honest reporting' cannot eliminate variance in income when taxable income is random. If the taxpayer reports $m$, he will have a different net income according to whether he is assessed high or low when audited.

Another second-best problem is whether taxpayers may prefer some randomness in assessed taxable income when revenues are returned to taxpayers as a lump-sum rebate. In this problem, all other tax and enforcement parameters are held fixed, while additional revenue collected through randomness is returned to taxpayers, to keep their mean net-of-tax income fixed.

We assume the government keeps the amount of revenue collected when $d=0$. A lump-sum rebate in amount $T(d)^{18}$ is returned: ${ }^{19}$

$$
T(d)=R[r(\cdot), d, p, t]-R[r(\cdot), 0, p, t] .
$$

Proposition 2 showed that when allowing randomness saves costs, taxpayers will always prefer some uncertainty to none. The following example shows that taxpayers may prefer randomness in tax assessment even when there is no cost saving, although this is not generally true. The risk-averse taxpayer's distaste for uncertainty may (or may not) be dominated by the fact that increased revenues may smooth consumption over different states of the world.

An increase in randomness, $d$, increases expected utility in the following amount, beginning at a value of $d$ for which $r(\cdot)<m-d$. (We suppress the arguments $p$ and $t$, since they remain fixed for the remainder of this section.)

$$
\begin{aligned}
\frac{\mathrm{d} E U[r(\cdot), T(d), d]}{\mathrm{d} d}= & {\left[(1-p) U^{\prime}\left[w_{\mathrm{NA}}\right]+(p / 2)\left[U^{\prime}\left[w_{\mathrm{AL}}\right]+U^{\prime}\left[w_{\mathrm{AH}}\right]\right] T^{\prime}(d)\right.} \\
& -(p / 2) t(1+f)\left[U^{\prime}\left[w_{\mathrm{AH}}\right]-U^{\prime}\left[w_{\mathrm{AL}}\right]\right]
\end{aligned}
$$

Substituting for $U^{\prime}\left[w_{\mathrm{NA}}\right]$ from the first-order condition (4), and for $T^{\prime}(d)$ from (2), yields:

\footnotetext{
${ }^{18}$ This means that $m$ is augmented by $T(d)$ in the expressions $w_{\mathrm{NA}}, w_{\mathrm{AH}}$ and $w_{\mathrm{AL}}$. For example, $w_{\mathrm{NA}}=m+T(d)-\operatorname{tr}(\cdot)$.

The arguments to the optimal function $r(\cdot)$ must be augmented to include the rebate $T$, as in $r(d, T, p, t)$, since the amount of taxable income will typically depend on how rich the taxpayer is. The taxpayer does not account for the effect on lump-sum transfers of changing his reported income. He takes income $m+T(d)$ as fixed and is not taxed on his rebate $T(d)$, just as if it were a government expenditure on public goods. $T(d)$ is the lump-sum rebate that balances the budget on average. If there is a large number of identical taxpayers, then the budget will be close to balanced with high probability, and each taxpayer will realize that the effect on $T(d)$ of his personal evasion decision is small.
} 


$$
\begin{aligned}
& \frac{\mathrm{d} E U[r(\cdot), T(d), d]}{\mathrm{d} d} \\
& \left.=t(1+f)(p / 2)[1-p(1+f)]\left(U^{\prime}\left[w_{\mathrm{AH}}\right]+U^{\prime}\left[w_{\mathrm{AL}}\right]\right) r_{d}(\cdot)\right) \\
& \quad-(p / 2) t(1+f)\left(U^{\prime}\left[w_{\mathrm{AH}}\right]-U^{\prime}\left[w_{\mathrm{AL}}\right]\right) .
\end{aligned}
$$

When $r_{d}(\cdot)>0$, the first term is positive, while the last term is negative. Whether expected utility rises or falls with randomness depends on $r_{d}(\cdot)$, the responsiveness of reported income to randomness, as given in eq. (6). No simple condition on the utility function and parameters will guarantee that utility rises or falls. With constant absolute risk aversion, utility must fall, although with decreasing absolute risk aversion, utility may rise or fall. The example below, in which utility rises with randomness, has nonincreasing absolute risk aversion.

When $d$ increases, consumption, when not audited, must decrease. Suppose $w_{\mathrm{NA}}$ increased. That is, suppose $m+T(d)-\operatorname{tr}(\cdot)$ rose with $d$. Then average income when audited must fall, since expected tax payments net of transfers are held constant. The average consumption when audited is the average of $w_{\mathrm{AL}}$ and $w_{\mathrm{AH}}$, which is $[m+T(d)-\operatorname{tr}(\cdot)]-t(1+f) m+t(1+f) r(\cdot)$. Since the report increases with $d$, average income can fall only if the first term falls, but that is a contradiction.

Thus, when $r(\cdot)<m-d$, an increase in uncertainty induces a decrease in the gap between consumption when the taxpayer is not audited and the average consumption when he is audited. The remaining question is whether this reduction in the gap can compensate for the increased variance in consumption, conditional on audit. The following example shows that it may.

Example. Suppose preferences are given by

$$
u(w)= \begin{cases}\log w & 0<w<(1 / 0.16)=6.67 \\ 0.15(w+5.9808), & w>(1 / 0.16)=6.67\end{cases}
$$

This utility function is concave, continuous, and exhibits nonincreasing absolute risk aversion. We take $m-10, t=0.4, p-0.15$, and $f-2$. For these values, and when $d$ is less than 2 , income is in the range of decreasing absolute risk aversion when the taxpayer is audited, but is in the linear portion of the utility function when no audit occurs. The appendix demonstrates that, in this example, expected utility first rises with $d$, and reaches a maximum at $d=1.6$.

\section{Conclusion}

We first showed that the optimal enforcement policy requires some 
randomness in the assessment of taxable income whenever reducing randomness is costly. This is true whether the saved costs are rebated through taxes, or whether a fixed amount of revenue is maintained by reducing the probability of audit when randomness increases.

We also considered the optimal amount of randomness in two second-best problems: that of using randomness as an enforcement parameter, when the tax code and fines are fixed, and that of using randomness to enhance revenue when all other tax and enforcement parameters are fixed. In the enforcement problem, it may or may not be optimal to make assessed taxable income as random as possible. In the second problem, taxpayers may prefer some randomness in tax assessment when they are rebated the additional revenue collected, either directly or through public goods that they value at least as much as the dollars required to produce the public goods.

Thus, risk aversion does not necessarily imply that uncertainty about the tax assessment is suboptimal.

One implication of this study is that, if the enforcement agency maximizes net revenue, it will have a different view of randomness than if it maximizes taxpayers' expected utility. An interpretation of Proposition 1 is that, if the enforcement agency maximizes net revenue with the tax code and allowable fines fixed, more randomness is often preferred. But more randomness may or may not enhance expected utility. Slemrod and Yitzhaki (1987) showed that a similar difference arises with respect to the optimal enforcement budget with no uncertainty in assessed taxable income. With the tax code and allowable fines fixed, an enforcement agency that maximizes net revenue will want a larger enforcement budget than does an enforcement agency that maximizes expected utility. These divergences suggest caution in interpreting enforcement models that assume the agency's objective is to maximize revenue. Benevolent tax collection agencies may not in fact maximize revenue, and, indeed, should not. Rather, the tax system and enforcement policy should be chosen jointly to maximize social welfare.

In the simple model we have studied, the only social cost of evasion is the uncertainty in consumption that accompanies it. Tax evasion may also affect horizontal and vertical equity. Vertical equity cannot be studied in our model, since we have assumed all taxpayers have the same income. One may consider it horizontally inequitable that some taxpayers get audited and fined, while others do not. If these elements are introduced, policies that reduce tax evasion are more likely to appear beneficial from a social welfare perspective.

That uncertainty may enhance revenue has recently been corroborated by Reinganum and Wilde (1987) for the case that the taxpayer is uncertain of enforcement costs and therefore uncertain whether his tax debt will be collected, and by Scotchmer $(1988 \mathrm{a}, 1988 \mathrm{~b})$ for the case that, although 
auditors would agree on taxable income, the taxpayer is ignorant of aspects of the tax law and must choose whether to resolve uncertainty. In this paper, we have shown not only that randomness in assessed taxable income generally enhances revenue, but that some randomness is optimal from the point of view of social welfare, if randomness is costly to reduce.

\section{Appendix}

Proof of Lemma 1 . At $d=0, r(0, p, t)=m$, and the value of (4) is zero, since $w_{\mathrm{AH}}=w_{\mathrm{AL}}=w_{\mathrm{NA}}$ and $p=1 /(1+f)$. It follows that the value of $(5)$, which is less than the value of (4), is negative. Since $w_{\mathrm{AH}} \leqq w_{\mathrm{NA}}$ for every $d$ and $r$, and since (5) has negative value when $w_{\mathrm{AH}}=w_{\mathrm{NA}}$, it must be true that (5) has negative value for $w_{\mathrm{AH}}$ and $w_{\mathrm{NA}}$ close to $m(1-t)$; in particular, when $r$ is close to $m$ and $d$ is close to zero. Thus, it cannot occur that $m-d<r(d, p, t)<m+d$ for small $d$, since that would require (5) to have value greater than or equal to zero, a contradiction.

Hence, for $d$ close to zero, $r(d, p, t) \leqq m-d$. We now show that $r(d, p, t)$ cannot be less than $m-d$. Since $U(\cdot)$ exhibits nonincreasing absolute risk aversion, the third derivative of $U(\cdot)$ is positive, so the marginal utility $U^{\prime}(\cdot)$ is convex. Hence,

$$
\begin{gathered}
-(1-p) U^{\prime}\left[w_{\mathrm{NA}}\right]+p f\left[(1 / 2) U^{\prime}\left[w_{\mathrm{AL}}\right]+(1 / 2) U^{\prime}\left[w_{\mathrm{AH}}\right]\right] \\
\geqq-(1-p) U^{\prime}\left[w_{\mathrm{NA}}\right]+p f U^{\prime}\left[(1 / 2) w_{\mathrm{AL}}+(1 / 2) w_{\mathrm{AH}}\right] \\
\geqq-(1-p) U^{\prime}\left[w_{\mathrm{NA}}\right]+p f U^{\prime}\left[w_{\mathrm{NA}}\right]=0 .
\end{gathered}
$$

The latter equals zero because $p=1 /(1+f)$. Hence the value of $(4)$ is positive, rather than zero, which implies that $r(d, p, t)=m-d$ for $d$ sufficiently close to zero. Q.E.D.

Example. Since $p<1 /(1+f), r(\cdot)<m-d$ for small $d$. We will consider such values of $d$. The parameters have been chosen so that $w_{\mathrm{NA}}$ is in the domain where utility is linear, while $w_{\mathrm{AI}}$ and $w_{\mathrm{AH}}$ are in the domain where utility is logarithmic. The first-order condition (4) then becomes:

$$
\begin{gathered}
-(1-p) s+\frac{(p / 2) f}{m-t(m-d)-t f(m-d-r)+T} \\
+\frac{(p / 2) f}{m-t(m+d)-t f(m+d-r)+T}=0 .
\end{gathered}
$$

Provided there is a solution to this equation, our hypotheses above are 
correct and (A.1) describes the optimal $r(T, d)$, since there is only one value of $r$ that satisfies (4) or (5). We suppress the parameters $(p, t)$ in the expression for $r(\cdot)$ because they stay fixed in this discussion.

Solving (A.1) for $r(\cdot)$ yields:

$$
r()=\frac{b+\sqrt{b^{2}-4 a c}}{2 a}-\frac{T}{l f},
$$

where

$$
\begin{aligned}
a & =2 t s(1-p) / p \\
b & =2+a^{2 m(1-t(1+f))} \frac{m}{t f}, \\
c & =a-t(m-d)(1+f) \\
t f & \frac{m-t(m+d)(1+f)}{t f}+\frac{2 m(1-t(1+f))}{t f} \\
& =a\left[\frac{m^{2}(1-t(1+f))^{2}}{(t f)^{2}}-d^{2}\left[\frac{1+f}{f}\right]^{2}\right]+\frac{2 m(1-t(1+f))}{t f} .
\end{aligned}
$$

We have disregarded the smaller root of the quadratic equation because $w_{\mathrm{AH}}$ is then negative and outside the domain. One can see from this expression that

$$
\frac{\partial r(\cdot)}{\partial d}=2 a d\left[\frac{1+f}{f}\right]^{2}\left[b^{2}-4 a c\right]^{-0.5},
$$

which is positive for positive $d$ and equal to zero when $d=0$.

Although the representative individual takes the rebate $T$ as fixed, in equilibrium it must be that

$$
\begin{aligned}
T(d)= & {[t(1-p(1+f)) r(d, p, t)+m p t(1+f)] } \\
& -[t(1-p(1+f)) r(0,0)+m p t(1+f)] \\
= & t(1-p(1+f))(r(T(d), d)-r(0,0))
\end{aligned}
$$

where $r(0,0)$ is the report that would be made if $d=0$ and $T=0$.

Combining (A.2) and (A.4), we can express the equilibrium level of $r(\cdot)$ as a function of $d$ as: 


$$
r(T(d), d)=\frac{f}{(1+f)(1-p)}\left[X+\frac{(1-p(1+f))}{f} r(0,0)\right],
$$

where

$$
X=\frac{b+\sqrt{b^{2}-4 a c}}{2 a} .
$$

Then we can show that:

$$
\frac{\partial r(\cdot)}{\partial d}=\frac{2 a d}{1-p}\left[\frac{1+f}{f}\right]\left[b^{2}-4 a c\right]^{-0.5}>0, \quad \text { if } d>0 .
$$

In our example, $m=10, t=0.4, p=0.15, f=2$, and $s=0.15$. In this case, (A.5) and (A.6) reduce to:

$$
\begin{aligned}
& r(\cdot)=4.28+0.576\left(4+4.16 d^{2}\right)^{0.5}, \\
& \partial r(\cdot) / \partial d=2.40 d\left(4+4.16 d^{2}\right)^{-0.5} .
\end{aligned}
$$

From $(15), \mathrm{d} E U(\cdot) / \mathrm{d} d$ becomes:

$$
\frac{-0.09+0.1188 d\left(4+4.16 d^{2}\right)^{-0.5}}{1.47-1.5 d+0.735\left(4+4.16 d^{2}\right)^{0.5}}+\frac{0.09+0.1188 d\left(4+4.16 d^{2}\right)^{-0.5}}{1.47+1.5 d+0.735\left(4+4.16 d^{2}\right)^{0.5}}
$$

At $d=0, \mathrm{~d} E U(\cdot) / \mathrm{d} d=0$, but $\mathrm{d} E U(\cdot) / \mathrm{d} d$ is positive for positive $d$. Expected utility is maximized when $d=1.6$.

\section{References}

Allingham, M.G. and A. Sandmo, 1972, Income tax evasion: A theoretical analysis, Journal of Public Economics, pp. 323-338.

Baldry, J.C., 1984, The enforcement of income tax laws: Efficiency implications, Economic Record 60, pp. 156-159.

Beck, P. and W. Jung, 1987, Taxpayer compliance under uncertainty, manuscript, University of Illinois.

Chang, F.R. and D.E. Wildasin, 1987, Randomization of commmodity taxes: An expenditure minimization approach, Journal of Public Economics 31, 329-346.

Cowell, Frank E., 1985, Public policy and tax evasion: Some problems, in: A. Wenig and W. Gaertner, eds., The economics of the shadow economy (Springer Verlag, Berlin).

Lee, Eunsang, 1987, Tax trcatment, uncertainty, and the IRS individual rulings program, manuscript, Stanford University.

Reinganum, J. and L. Wilde, 1987, A note on uncertainty in tax enforcement, manuscript, California Institute of Technology.

Roberts, S., 1979, Overview: The viewpoint of the tax lawyer, in: C.H. Gustafson, ed., Federal income tax simplification (Philadelphia, American Law Institute), pp. 137-159. 
Scotchmer, S., 1988a, Who profits from taxpayer confusion?, Economics Letters, forthcoming.

Scotchmer, S., 1988b, The effect of tax advisors on tax compliance, in: J. Roth and J. Scholz, eds., Why people pay taxes: A social science perspective (University of Pennsylvania Press, Philadelphia, PA), forthcoming.

Scotchmer, S. and J. Slemrod, 1987, Optimal obfuscation in tax enforcement, GSPP Working paper 126 (University of California, Berkeley, $\mathrm{C} \Lambda$ ).

Slemrod, J., 1988, Complexity, compliance costs, and tax evasion, in: J. Roth and J. Scholz, eds., Why people pay taxes: A social science perspective (University of Pennsylvania Press, Philadelphia, PA), forthcoming.

Slemrod, J. and S. Yitzhaki, 1987, The optimal size of a tax collection agency, Scandinavian Journal of Economics 89, 183-192.

Stiglitz, J., 1982, Utilitarianism and horizontal equity: The case for random taxation, Journal of Public Economics XI, pp. 1-33.

U.S. Department of the Treasury, 1984, Tax reform for fairness, simplicity and economic growth (U.S. Government).

Weiss, L., 1976, The desirability of cheating incentives and randomness the optimal income tax, Journal of Political Economy LXXXIV, pp. 13431352.

Yankelovich, Skelly and White, Inc., 1984, Taxpayer attitudes study: Final report (Internal Revenue Service, Washington, D.C.). 